\title{
Isothermal omega Assisted Alpha Phase Precipitation and Microstructural Evolution of an Aged Ti-30Nb-3Fe Alloy
}

\author{
Mariana G. de Mello ${ }^{a *}$ (), Fernando H. Costa ${ }^{b}$ (i), Victor Opini ${ }^{b}$, Arthur Resende ${ }^{b}$, \\ Alessandra Cremasco ${ }^{a}$ (D), Rubens Caram $^{b}$ (D) \\ ${ }^{a}$ Universidade de Campinas (UNICAMP), Escola de Ciências Aplicadas, 13484-350, Limeira, SP, Brasil. \\ ${ }^{b}$ Universidade de Campinas (UNICAMP), Escola de Engenharia Mecânica, 13083-860, Campinas, SP, Brasil.
}

Received: January 17, 2020; Revised: May 9, 2020; Accepted: May 12, 2020

\begin{abstract}
The mechanical behavior of metastable $\beta$ Ti alloys can be controlled through heat treatments. Thus, the relationship between the precipitation of $\alpha$ phase and the mechanical properties of these alloys is of special interest. In this work, the microstructure evolution of Ti-30Nb-3Fe alloy during aging heat treatments was evaluated using optical microscopy, scanning electron microscopy and X-ray diffraction. Moreover, Vickers hardness and elastic modulus were measured as a function of aging time. Finally, the ultimate strength and ductility of the alloy aged at $500{ }^{\circ} \mathrm{C}$ was assessed by tensile tests. In comparison to a Ti-30Nb alloy, the addition of Fe lowered the $\beta$-transus temperature, decreased the martensite start temperature to a value below room temperature, increased the precipitation temperature and reduced the dissolution temperature of $\omega$ phase, and lastly, decreased the $\alpha$ phase precipitation temperature. Low heating rates enabled isothermal $\omega$ phase precipitation and growth, providing favorable conditions for $\alpha$ phase precipitation and increasing the amount of $\alpha$ phase precipitates. Compared to the solution heat-treated and water-quenched condition, aging heat-treated Ti-30Nb-3Fe alloy presented higher Vickers hardness and mechanical strength, without significant loss of ductility.
\end{abstract}

Keywords: Ti alloys, biomaterial, thermomechanical treatment, Vickers hardness, elastic modulus.

\section{Introduction}

Metastable $\beta$ Ti alloys are widely used in the manufacturing of load-bearing components for aerospace and medical applications ${ }^{1-4}$. Besides their excellent corrosion resistance and improved biocompatibility, the extensive use of $\mathrm{Ti}$ alloys is strongly based on their mechanical behavior, which results from Ti allotropy combined with a range of alloying elements and suitable processing routes. Upon heating, the $\alpha$ phase (hcp) of CP Ti is transformed into the $\beta$ phase (bcc) at $882.5^{\circ} \mathrm{C}$ (for pure Ti), also known as $\beta$-transus temperature. The addition of alloying elements and application of proper thermomechanical processing allows for tailoring of phase transformations and hence, control of the mechanical behavior ${ }^{5,6}$.

The addition of $\mathrm{Nb}$ to $\mathrm{Ti}$ has been investigated because it lowers the $\beta$-transus temperature, resulting in full $\beta$ phase stabilization at room temperature and also reducing the elastic modulus ${ }^{7-9}$. Furthermore, $\mathrm{Nb}$ is highly biocompatible, enabling its alloys to be employed as biomaterials ${ }^{10}$. Fe is another interesting Ti alloying element. Previous reports suggest that the addition of Fe to the Ti-Nb system refines the $\alpha$ phase precipitates ${ }^{11}$, stabilizes the $\beta$ phase ${ }^{12}$, decreases the elastic modulus ${ }^{7}$, and may also reduce its cost. Therefore, $\mathrm{Ti}-\mathrm{Nb}-\mathrm{Fe}$ alloys can potentially be used in the manufacture of devices for biomedical implants.

In addition to their low elastic modulus, Ti alloys designed for use in hard tissue implants must possess both

*e-mail: mariana.gerardi@gmail.com high mechanical strength and high ductility, and one way of achieving this goal is to control the precipitation of $\alpha$ phase in the $\beta$ phase matrix ${ }^{13}$. The mechanical behavior of $\beta$ Ti alloys can be tailored by subjecting solution heat-treated samples to aging heat treatments, inducing the precipitation of $\alpha$ phase, which is harder than $\beta$ phase. Upon aging, the decomposition of metastable $\beta$ phase and precipitation of $\alpha$ phase are complex phenomena that involve the dissolution of the athermal $\omega$ phase, precipitation and dissolution of isothermal $\omega$, and finally, precipitation of $\alpha$ phase. Typically, $\alpha$ phase precipitation is based on heterogeneous nucleation assisted by microstructural heterogeneities, such as grain boundaries, $\beta / \beta^{\prime}$ interfaces resulting from phase separation, and eventually, particles of $\omega$ phase dispersed in the $\beta$ phase $^{14}$. Nucleation, which involves $\omega$ phase acting as nucleation sites, plays a key role in $\alpha$ phase precipitation and its distribution in the $\beta$ matrix $^{15,16}$. It is known that under favorable conditions, isothermal $\omega$ phase dissolution can result in a microstructure consisting of highly refined and well dispersed $\alpha$ precipitates. The mechanism involved in $\omega$-assisted nucleation of $\alpha$ phase is based on the direct transformation of $\omega$ phase into $\alpha$ phase or on solute partitioning in the $\beta$ phase close to $\omega$ particles ${ }^{14}$. In a recent report, results obtained by an aging heat treatment of Ti-30Nb alloy carried out at temperatures close to $400{ }^{\circ} \mathrm{C}$ indicated that isothermal $\omega$ phase, albeit metastable, remained in the microstructure for long periods without $\alpha$ phase precipitation, which is in good accordance with the temperature vs. time map suggested by 
Ivasishin et al. ${ }^{17}$. When the aging temperature was increased, dissolution of isothermal $\omega$ phase and $\alpha$ phase precipitation took place rapidly ${ }^{18}$. Alpha phase precipitation based on the $\omega$ phase assisted mechanism depends on the misfit between $\omega / \beta$ phases $^{14,15}$. It is well established in the literature that, in high misfit systems, the ledges between $\omega / \beta$ phases act as nucleation sites for the $\alpha$ phase, but the precise mechanism in low misfit systems (Ti-Nb, for instance) is not well known ${ }^{19}$. However, regardless of misfit, $\omega$ phase precipitates contribute to increase the driving force for $\alpha$ precipitation in Ti alloys ${ }^{14,16,20}$

An additional factor that strongly affects $\alpha$ phase precipitation in highly stabilized $\beta$ Ti alloys is the heating rate applied to reach the final aging heat treatment temperature ${ }^{17,21}$. This is due to the prolongation of the holding time in the $\omega$ phase formation temperature zone, generating a different number of nucleation sites for $\alpha$ phase precipitation. The effects of the heating rate on $\alpha$ phase precipitation were investigated previously ${ }^{17,22}$ and indicated that the application of low heating rates followed by subsequent aging could provide a fine and well-dispersed $\alpha+\beta$ microstructure, with an interesting strength-ductility balance.

Therefore, the aim of this investigation was to describe the aging response in the $\mathrm{Ti}-30 \mathrm{Nb}-3 \mathrm{Fe}$ alloy in the $\beta$ quenched condition in order to optimize fine $\alpha$ phase precipitates in the $\beta$ phase matrix. Efforts are focused on determining the effect of heating rates at different final aging temperatures and aging holding times. Lastly, correlations between microstructure and mechanical properties were also investigated.

\section{Experimental Procedure}

The Ti-30Nb-3Fe (wt.\%) alloy was produced by voltaic arc melting using non-consumable tungsten electrodes and a water-cooled copper crucible under a highly pure argon atmosphere. High-purity $\mathrm{Ti}, \mathrm{Nb}$ and Fe elements were used as raw materials and compositional homogeneity was achieved by remelting and flipping the ingots several times. This was followed by heat-treating the samples at $1000^{\circ} \mathrm{C}$ for $24 \mathrm{~h}$ with subsequent water quenching. The resulting ingots were cold-rolled in multiple passes to decrease their thickness by up to $70 \%$ without intermediate annealing, thereby obtaining $2 \mathrm{~mm}$ thick plates. These plates were annealed at $700,800,900$ and $1000^{\circ} \mathrm{C}$ for $1 \mathrm{~h}$ and water-quenched in order to reduce the grain size. The samples' chemical compositions were measured using the X-ray fluorescence (XRF) technique (Shimadzu 7000 EDX-7000). The contents of interstitial elements ( $\mathrm{O}$ and $\mathrm{N}$ ) were measured using a Leco TC400 analyzer.

A Kroll etching solution ( $6 \mathrm{~mL}$ of $\mathrm{HNO}_{3}, 3 \mathrm{~mL}$ of $\mathrm{HF}$ and $91 \mathrm{~mL}$ of $\mathrm{H}_{2} \mathrm{O}$ ) was employed in the metallographic preparation. The samples' microstructure was investigated by optical microscopy (OM) using a Olympus BX60M microscope, scanning electron microscopy (SEM) using a Zeiss EVO 15 microscope, and the crystalline phase was identified by X-ray diffraction (XRD) using a PANalytical $\mathrm{X}$ 'Pert diffractometer equipped with a Pixel X-ray detector, operating at $40 \mathrm{kV}$ and $30 \mathrm{~mA}$, with $\mathrm{CuK} \alpha$ radiation, $\lambda=0.15406 \mathrm{~nm}$.
To evaluate the $\beta$-transus temperature, recrystallized samples were heated to the $\beta$ phase field in an argon atmosphere. To monitor their actual temperature, thermocouples were inserted into the samples and an iterative procedure was employed to measure the $\beta$-transus temperature: samples were heat treated at a certain temperature, from 569 to $593{ }^{\circ} \mathrm{C}$, for $15 \mathrm{~min}$, after which they were water quenched. Their microstructure was then characterized by the method described in the previous paragraph. Whenever $\alpha$ precipitates were found in the $\beta$ matrix, the procedure was repeated at a higher solution temperature. This procedure was carried out until the correct $\beta$-transus temperature was found and performed three times to take into account possible experimental errors.

Next, the samples were sealed in quartz tubes under an argon atmosphere and heat-treated at 400 and $500^{\circ} \mathrm{C}$, with subsequent water quenching. In order to reach the aging heat treatment temperature, three different heating rates $\left(1,10\right.$ and $30^{\circ} \mathrm{C} / \mathrm{min}$ ) were employed.

Vickers hardness was measured using a Buehler hardness tester with a $1 \mathrm{kgfload}$ applied for $10 \mathrm{~s}$. The average hardness of each sample was determined from 10 measurements. The elastic modulus was measured using the pulse-echo acoustic emission technique with a Panametrics-NDT 5072PR pulse receiver equipped with transducers operating at $5 \mathrm{MHz}$. Tensile tests were performed in an MTS 810 universal testing machine, with a strain rate of $1 \mathrm{~mm} / \mathrm{min}$. The samples were prepared by water jet cutting and machining, as shown in Figure 1.

\section{Results and Discussion}

The chemical compositions of arc melted and cold rolled samples were analyzed and the results indicated that the experimental composition matched the nominal composition. The levels of oxygen and nitrogen were 0.16 and 0.0083 wt. $\%$, respectively, and were in accordance with the ASTM-F67-13 standard (Table 1).

The recrystallization annealing heat treatment was carried out at different temperatures to experimentally achieve the best condition for the samples' grain size. According to Ivasishin et al. ${ }^{17}$, microstructural heterogeneities such as grain boundaries improve the precipitation mechanism. Therefore, the aim was to obtain the finest grain size in order to maximize the number of defects. Figure 2 shows optical micrographs

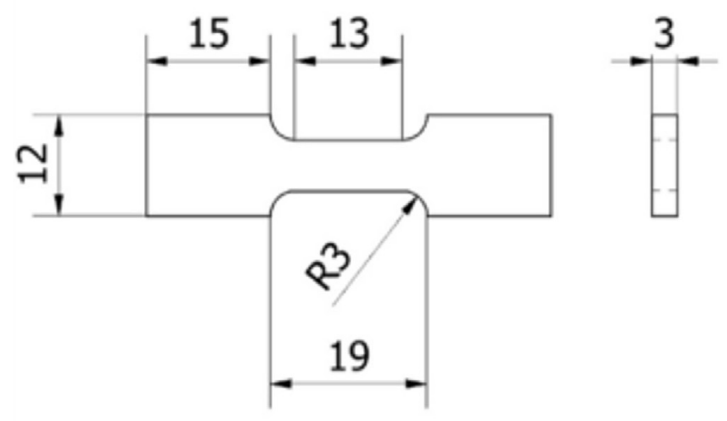

Figure 1. Schematic diagram of tensile tests specimens ${ }^{23}$.

Table 1. The chemical composition obtained by X-ray fluorescence spectrometry.

\begin{tabular}{cccccc}
\hline Element & $\mathrm{Ti}$ & $\mathrm{Nb}$ & $\mathrm{Fe}$ & $\mathrm{O}$ & $\mathrm{N}$ \\
\hline Composition (wt.\%) & Balance & $30.2 \pm 0.5$ & $3.3 \pm 0.4$ & $0.16 \pm 0.02$ & $0.0083 \pm 0.0004$ \\
\hline
\end{tabular}


and the grain size of Ti-30Nb-3Fe alloy after cold-rolling and recrystallization annealing at 700,800 and $900{ }^{\circ} \mathrm{C}$ for $1 \mathrm{~h}$. The finest grain size was achieved at the lowest temperature, i.e., $700{ }^{\circ} \mathrm{C}$, which explains its choice for the recrystallization heat treatment. In this condition, the grain size measured by the intercept method, as specified by ASTM E112-96, was around $30 \mu \mathrm{m}$.
In order to optimize the aging heat treatment conditions, the $\beta$-transus temperature of the Ti-30Nb-3Fe alloy was investigated by heat treating the samples at 569, 572, 577, 580,585 and $593{ }^{\circ} \mathrm{C}$ for $15 \mathrm{~min}$ and then water quenching them. These initial temperatures were selected based on the $\mathrm{Ti}-\mathrm{Nb}$ phase diagram ${ }^{24}$. The $\alpha$ phase was detected in all these conditions, except for the highest temperature (Figure 3),
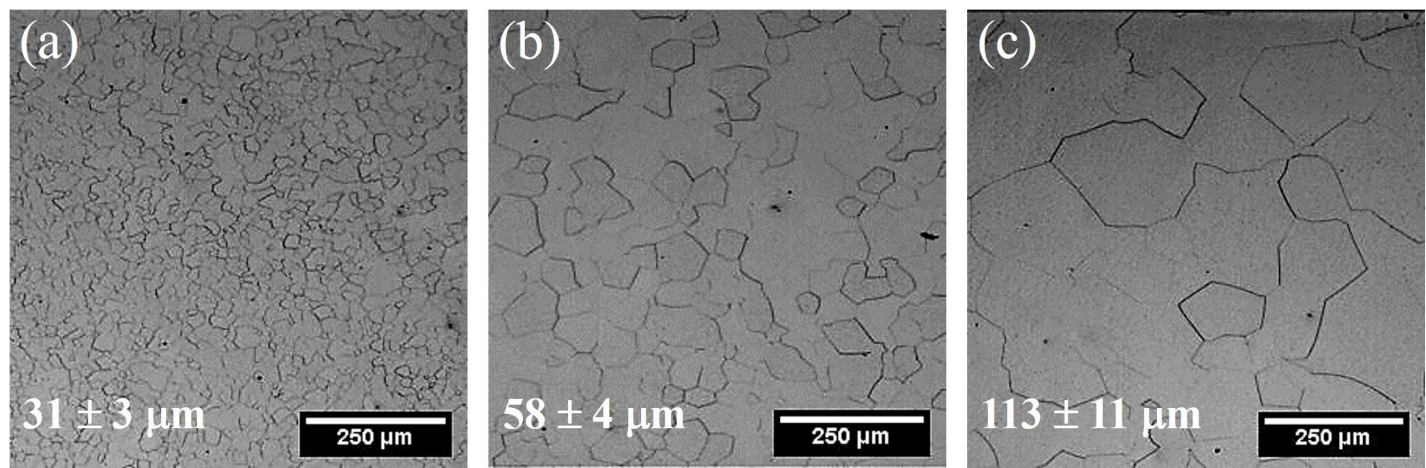

Figure 2. Optical micrographs and grain size of the microstructure obtained after recrystallization annealing at: (a) $700{ }^{\circ} \mathrm{C}$, (b) $800{ }^{\circ} \mathrm{C}$, and $900{ }^{\circ} \mathrm{C}$.
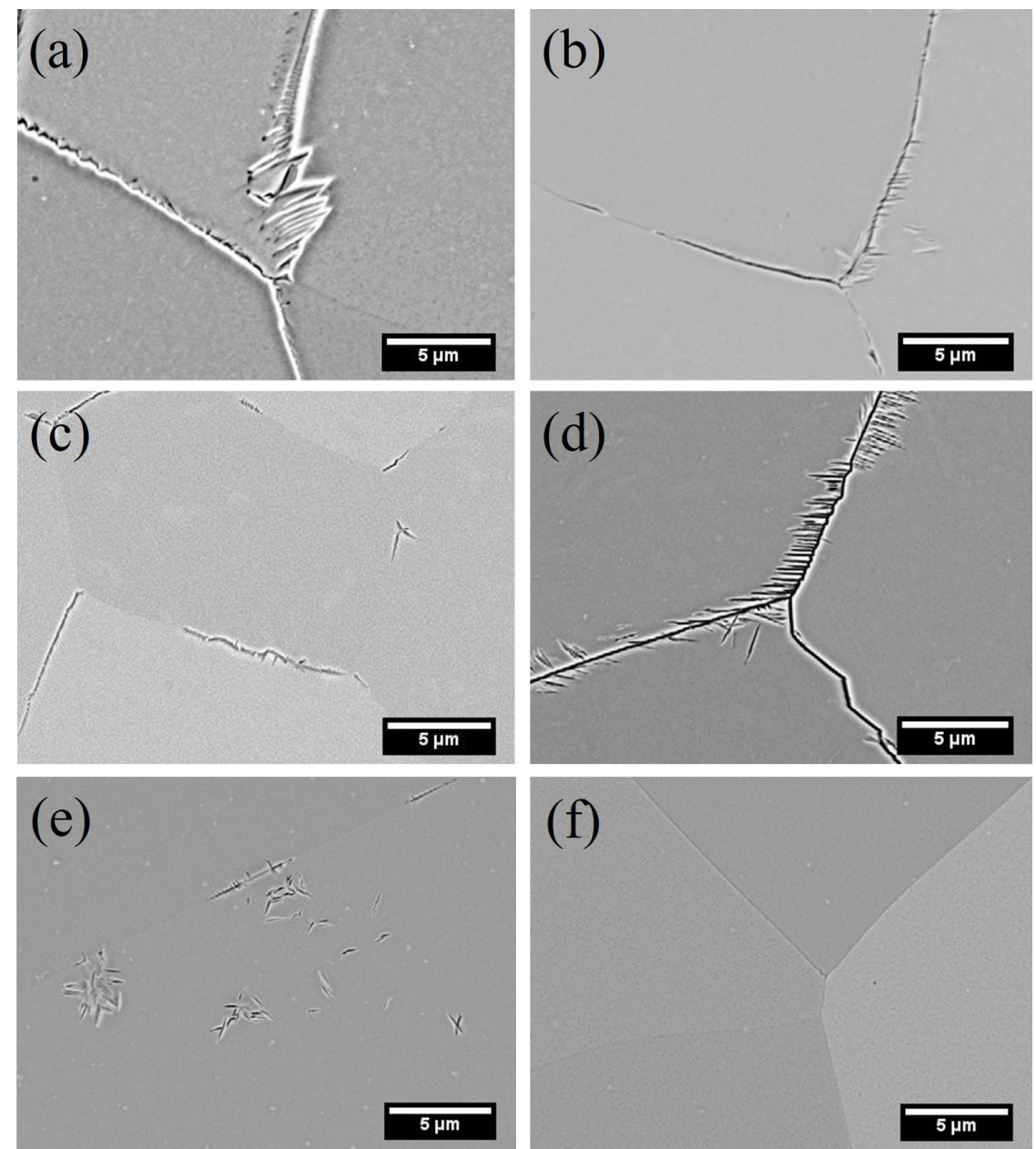

Figure 3. Microstructures of Ti-30Nb-3Fe alloy treated for 15 minutes at (a) $569^{\circ} \mathrm{C}$, (b) $572{ }^{\circ} \mathrm{C}$, (c) $577{ }^{\circ} \mathrm{C}$, (d) $580{ }^{\circ} \mathrm{C}$, (e) $585{ }^{\circ} \mathrm{C}$, and (f) $593{ }^{\circ} \mathrm{C}$ with subsequent water quenching. The $\alpha$ phase precipitation can be seen from (a) to (e) while (f) shows no $\alpha$ phase precipitation. SEM micrographs recorded in backscattered electron imaging mode. 
(a)

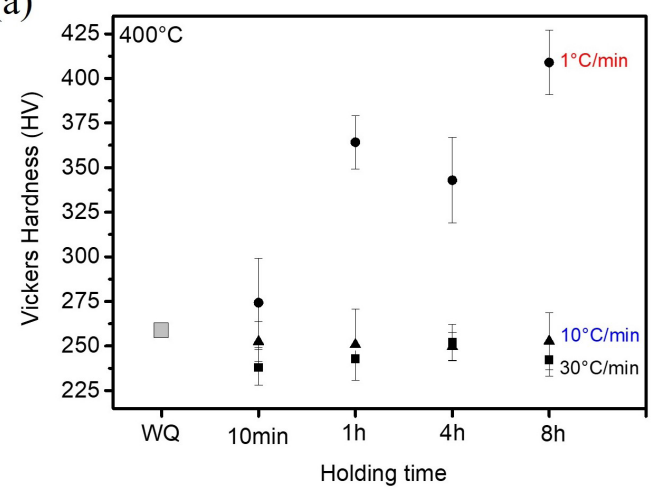

(b)

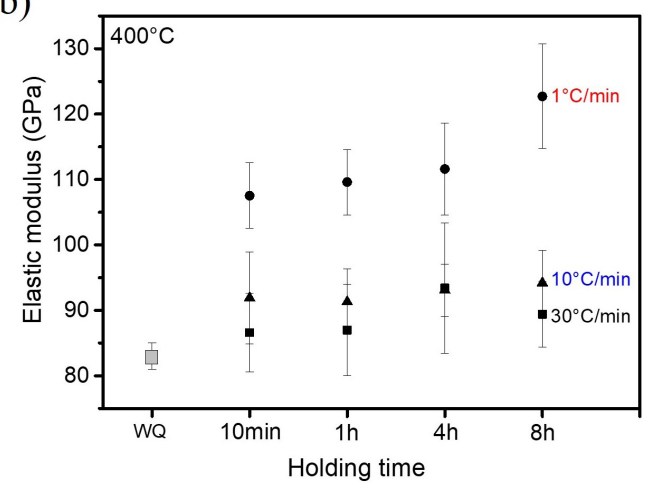

Figure 4. (a) Vickers hardness and (b) elastic modulus of each of the aged samples heated to $400{ }^{\circ} \mathrm{C}$ at a heating rate of 30,10 and $1{ }^{\circ} \mathrm{C} / \mathrm{min}$ for $10 \mathrm{~min}, 1 \mathrm{~h}, 4 \mathrm{~h}$ and $8 \mathrm{~h}$. Measurements of the WQ (solution heat treated and water quenched) sample were plotted for comparison.

leading to the conclusion that the $\beta$-transus temperature of the Ti-30Nb-3Fe alloy is between 585 and $593^{\circ} \mathrm{C}$.

According to the $\mathrm{Ti}-\mathrm{Nb}$ phase diagram ${ }^{24}$, the $\beta$-transus temperature of the Ti-30Nb alloy is approximately $614^{\circ} \mathrm{C}$. The addition of Fe reduces the $\beta$-transus temperature, and according to theoretical calculations ${ }^{25}$, is approximately $589{ }^{\circ} \mathrm{C}$ for Ti-30Nb-3Fe. This theoretical temperature was entirely consistent with that measured in this study (between 585 and $593{ }^{\circ} \mathrm{C}$ ). Since aging heat treatments should be performed at temperatures below the $\beta$-transus temperature, the aging temperatures selected were 400 and $500{ }^{\circ} \mathrm{C}$.

The initial condition of the samples for all the aging heat treatments was the solution heat treatment followed by water quenching, which produced microstructures composed of $\beta$ and athermal $\omega$ phases, identified in a previous paper ${ }^{11}$ by $\mathrm{XRD}$ and TEM due to small volume fraction and nanometric size of the athermal $\omega$ phase. The Vickers hardness and elastic modulus of the Ti-30Nb-3Fe alloy after $\beta$ solution heat treatment followed by rapid quenching were measured and were found to be $259 \pm 3 \mathrm{HV}$ and $83 \pm 2 \mathrm{GPa}$, respectively.

Optimization of the aging heat treatment temperature was also based on data available on phase transformation temperatures of the Ti-30Nb-3Fe alloy ${ }^{7,11,26}$. It is known that adding Fe to Ti-30Nb alloy results in an increase in the $\beta$ phase stability and a decrease in the martensite start temperature, eventually shifting it to values below room temperature. As a result, no evidence of martensite decomposition was detected in the thermal analysis of Ti-30Nb-3Fe alloy carried out previously ${ }^{11}$. The corresponding DSC curve also showed the exothermic reaction $\beta \rightarrow \omega$ occurring at approximately $340^{\circ} \mathrm{C}$ in Ti-30Nb-3Fe alloy and the dissolution of this metastable phase at temperatures close to $430{ }^{\circ} \mathrm{C}$. For comparison, the DSC results from Ti-30Nb alloy ${ }^{11}$ revealed that $\beta \rightarrow \omega$ occurred near $300{ }^{\circ} \mathrm{C}$ and the dissolution of $\omega$ phase at around $460^{\circ} \mathrm{C}$. Therefore, the addition of $\mathrm{Fe}$ to the Ti-Nb alloys increased the $\omega$ phase starting temperature and decreased $\omega$ phase dissolution temperatures, decreasing the temperature range in which $\omega$ phase is present in this system. The addition of $\mathrm{Fe}$ also decreased the $\alpha$ phase precipitation temperature, as expected, since $\mathrm{Fe}$ is a $\beta$ stabilizer ${ }^{11}$.

Initially, solution heat-treated and water quenched Ti-30Nb-3Fe samples were aged at $400{ }^{\circ} \mathrm{C}$, applying

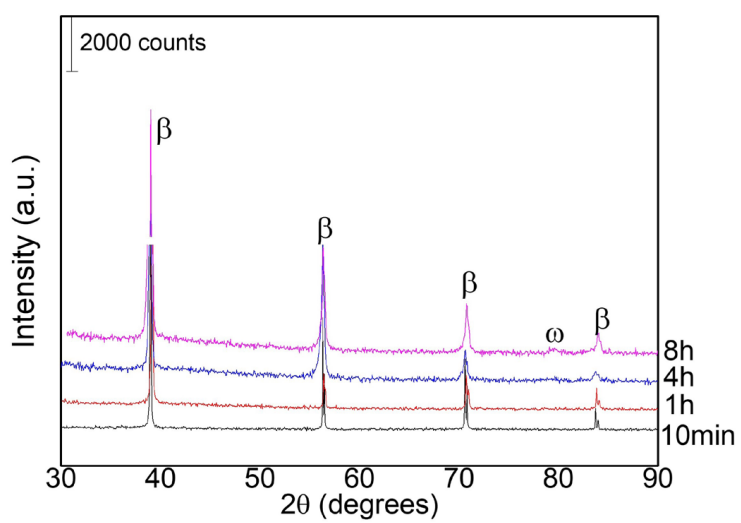

Figure 5. XRD patterns of each of the aged samples heated to $400{ }^{\circ} \mathrm{C}$ at a heating rate of $1^{\circ} \mathrm{C} / \mathrm{min}$ for $10 \mathrm{~min}, 1 \mathrm{~h}, 4 \mathrm{~h}$, and $8 \mathrm{~h}$.

different heating rates $\left(1,10\right.$ and $\left.30^{\circ} \mathrm{C} / \mathrm{min}\right)$ up to the final aging temperature. For each heating rate applied, samples were aged at $400{ }^{\circ} \mathrm{C}$ for $10 \mathrm{~min}, 1 \mathrm{~h}, 4 \mathrm{~h}$, and $8 \mathrm{~h}$. It was observed that Vickers hardness and elastic modulus measured in samples heated at 10 and $30{ }^{\circ} \mathrm{C} / \mathrm{min}$ did not present differences when compared to the $\beta$ solution heat-treated and quenched samples. This meant that the heating rates applied here hindered isothermal $\omega$ phase precipitation. The application of a lower heating rate $\left(1{ }^{\circ} \mathrm{C} / \mathrm{min}\right)$ resulted in Vickers hardness and elastic modulus values that increased with the aging holding time, as shown in Figure 4.

Figure 5 shows the $\mathrm{X}$-ray patterns of Ti-30Nb-3Fe alloy aged to $400^{\circ} \mathrm{C}$ at a heating rate of $1{ }^{\circ} \mathrm{C} / \mathrm{min}$ for $10 \mathrm{~min}, 1 \mathrm{~h}$, $4 \mathrm{~h}$ and $8 \mathrm{~h}$. The nanometric $\omega$ phase was detected by XRD after only $8 \mathrm{~h}$ of holding time when its volume fraction was appreciable. Precipitation of isothermal $\omega$ phase probably started earlier, during a shorter aging holding time, but its low volume fraction prevented its detection by XRD. Despite the fact that only $\beta$ phase peaks were detected in some of the XRD patterns, higher values of hardness suggest that the heating rate applied $\left(1{ }^{\circ} \mathrm{C} / \mathrm{min}\right)$ provided favorable conditions for the formation and growth of isothermal $\omega$ phase. The XRD patterns of the Ti-30Nb-3Fe alloy samples aged at $400{ }^{\circ} \mathrm{C}$, applying heating rates of 10 and $30^{\circ} \mathrm{C} / \mathrm{min}$, showed only $\beta$ phase peaks. 
To intensify phase precipitation and obtain a microstructure composed of fine $\alpha$ phase precipitates in a $\beta$ phase matrix, the aging temperature was increased to $500{ }^{\circ} \mathrm{C}$. This heat treatment was first carried out for $30 \mathrm{~min}, 4 \mathrm{~h}$, and $16 \mathrm{~h}$, applying a heating rate of $30^{\circ} \mathrm{C} / \mathrm{min}$. Figure 6 illustrates the microstructure and XRD patterns after the aging heat treatments. The XRD patterns of this condition show $\alpha$ phase peaks only after $4 \mathrm{~h}$ of aging time, probably due to the low volume fraction of this phase in shorter holding times. Note that the $\alpha$ phase nucleates primarily and mostly at the grain boundaries, and was also more evident after $4 \mathrm{~h}$ of aging time. Figure 7 (a-b) shows Vickers hardness and elastic modulus measurements, which reveal that the hardness and elastic modulus of the sample aged for $30 \mathrm{~min}$ was lower than that of the solution heat-treated sample, due to athermal $\omega$ dissolution. Prolonging the aging holding time led to a slight increase in hardness and elastic modulus due to the growth of intragranular $\alpha$ phase precipitates.

To evaluate the effects of a lower heating rate on the precipitation of $\alpha$ phase and its distribution in the $\beta$ matrix, the same aging heat treatment was applied, but at a heating rate of $1{ }^{\circ} \mathrm{C} / \mathrm{min}$. This heating rate resulted in fine and homogeneously dispersed $\alpha$ phase precipitates. After $30 \mathrm{~min}$ of holding time at $500{ }^{\circ} \mathrm{C}$, the $\alpha$ phase precipitates were
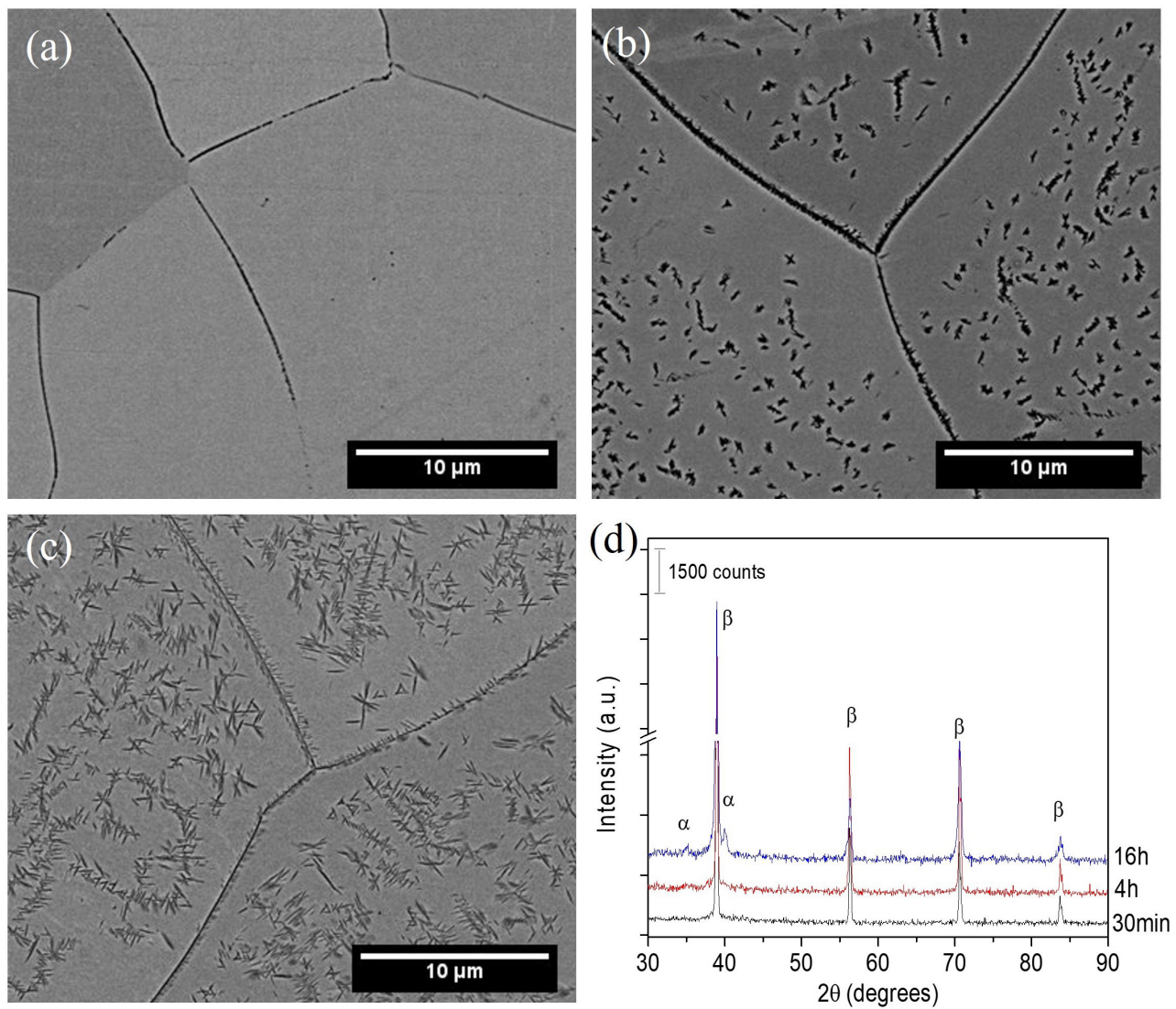

Figure 6. Microstructures of Ti-30Nb-3Fe alloy treated at $500{ }^{\circ} \mathrm{C}$, applying a heating rate of $30{ }^{\circ} \mathrm{C} / \mathrm{min}$ for (a) $30 \mathrm{~min}$, (b) $4 \mathrm{~h}$, (c) $16 \mathrm{~h}$ and (d) XRD patterns of each of the aged samples. SEM micrographs recorded in backscattered electron imaging mode with unetched samples.
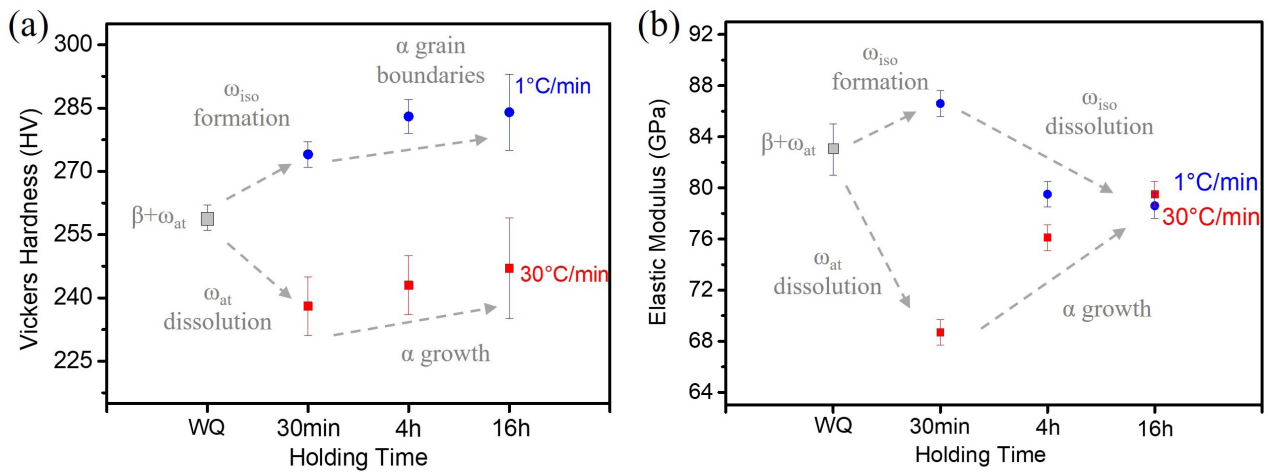

Figure 7. (a) Vickers hardness and (b) elastic modulus of each of the aged samples heated to $500{ }^{\circ} \mathrm{C}$ at heating rates of 30 and $1{ }^{\circ} \mathrm{C} / \mathrm{min}$ for $30 \mathrm{~min}, 4 \mathrm{~h}$, and $16 \mathrm{~h}$. 
smaller than $200 \mathrm{~nm}$. Increasing the holding time, even to $16 \mathrm{~h}$, resulted in an increase in $\alpha$ lath size, which was still very small, i.e., close to $500 \mathrm{~nm}$ (Figure 8 ). The refinement of $\alpha$ precipitates was an evidence of $\omega$-assisted $\alpha$ phase precipitation $^{14}$, through the $\alpha$ phase growing on $\omega$ phase and consuming it, despite the absence of $\omega$ peaks in the XRD patterns, which was probably due to its low volumetric fraction. The solute rejection of $\mathrm{Nb}$ and $\mathrm{Fe}$ during the $\alpha$ phase precipitation led to precipitate free zones became narrower after $16 \mathrm{~h}$ at $500{ }^{\circ} \mathrm{C}$ and heating rate of $1{ }^{\circ} \mathrm{C} / \mathrm{min}$.

The Vickers hardness and elastic modulus profiles of slowly heated samples are shown in Figure 7 (a-b). The increasing in the aging holding time caused the elastic moduli to decrease, probably due to the isothermal dissolution of $\omega$ phase. The Vickers hardness profile did not present the same trend. Although these values should decrease with the dissolution of $\omega$ phase, this decrease was compensated by $\alpha$ phase precipitation, especially at the grain boundaries, resulting in a slight increase in Vickers hardness.

The phase transformation mechanism of $\alpha$ phase precipitation in Ti-30Nb-3Fe alloy is influenced by several factors. According to Ivasishin et al. ${ }^{17}, \beta$ phase decomposition during an aging heat treatment causes competing $\omega$ and $\alpha$ phase precipitation mechanisms. Heating rate, aging temperature and holding time are essential to define the sequence of precipitation in continuous heating and isothermal aging. At low heating rates, isothermal $\omega$ precipitation occurs, providing favorable conditions for $\alpha$ precipitation. As the heating rate increases, isothermal $\omega$ precipitation becomes more complex, which hinders $\alpha$ phase nucleation. As the final aging temperature is increased to the temperature of $500^{\circ} \mathrm{C}$, the $\omega$-assisted $\alpha$ phase precipitation mechanism intensifies.

The temperature of $400{ }^{\circ} \mathrm{C}$ applied in the aging heat treatment did not favor $\alpha$ phase precipitation, which is in agreement with the results of thermal analysis ${ }^{11}$. Moreover, higher heating rates did not favor $\omega$ phase precipitation, so the Vickers hardness and elastic modulus values were similar to those of the solution heat-treated alloy. However, the lower heating rate favored precipitation and growth of isothermal $\omega$ phase, leading to Vickers hardness and elastic modulus values that increased with the aging holding time. Consequently, precipitation and growth of isothermal $\omega$ phase were intensified in samples subjected to lower heating rates, hence resulting in a higher density of $\alpha$ phase precipitates in the $\beta$ matrix, which, in turn, was a result of $\omega$ assisted nucleation $^{17}$.

The $\omega$ phase nucleation causes solute segregation, and when this phase decomposes, the $\beta$ phase matrix presents localized variations in composition ${ }^{27}$. According to Kobayashi et al. ${ }^{28}$, the dissolution of $\omega$ phase in the $\beta$ matrix during aging heat treatments changes the $\mathrm{Nb}$ content in the matrix, leading to favorable nucleation sites for $\alpha$ phase precipitation. In addition, according to Nag et al. ${ }^{14}$, $\alpha$ phase precipitation is based on a mixed mechanism with
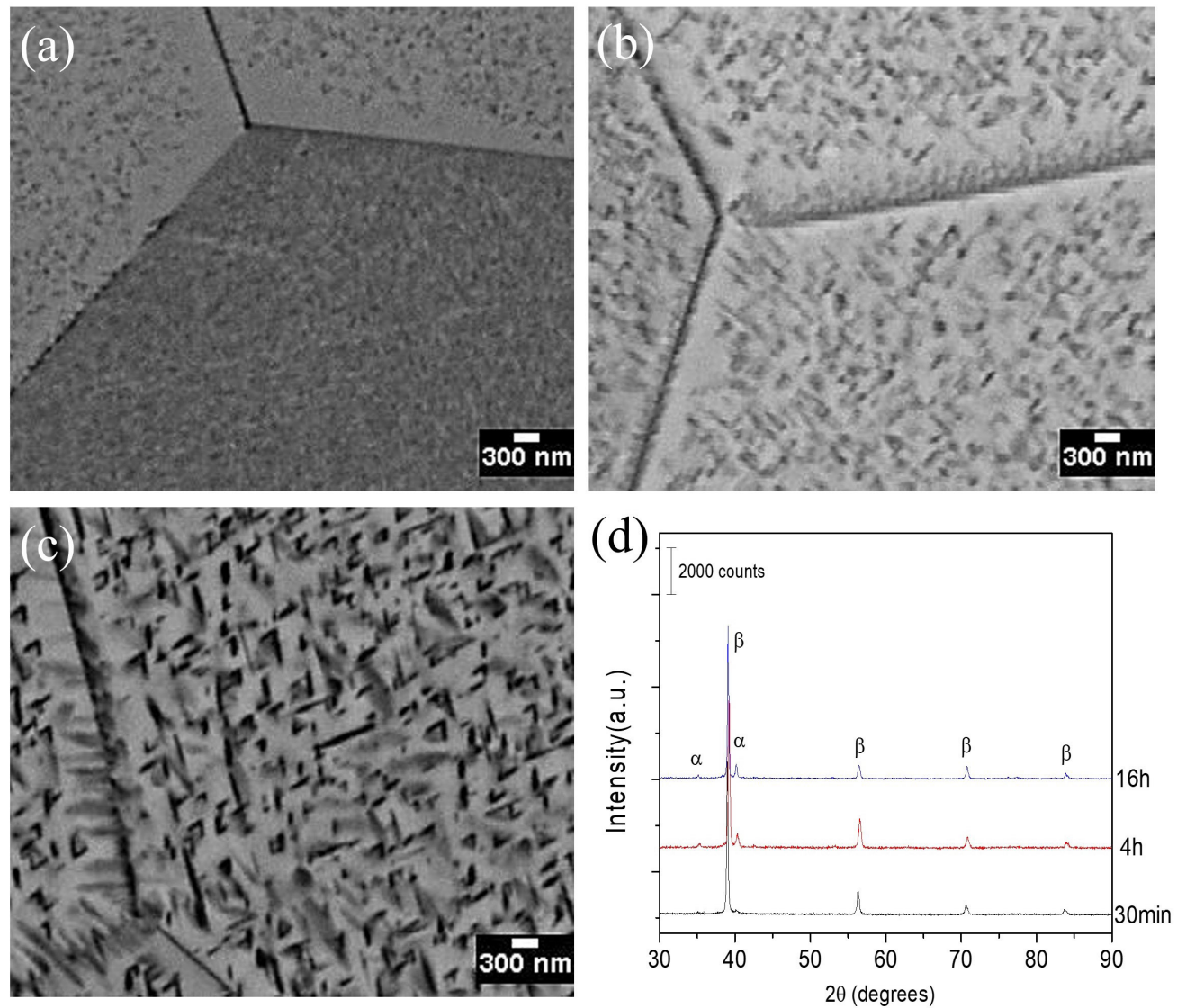

Figure 8. Microstructures of Ti-30Nb-3Fe alloy treated at $500{ }^{\circ} \mathrm{C}$, applying a heating rate of $1{ }^{\circ} \mathrm{C} / \mathrm{min}$ for (a) $30 \mathrm{~min}$, (b) $4 \mathrm{~h}$, and (c) $16 \mathrm{~h}$. (d) XRD patterns of each of the aged samples. SEM micrographs of unetched samples recorded in backscattered electron imaging mode. 
the displacive influence beyond the diffusional mode. In this case, the diffusion process leads to favorable nucleation sites where $\alpha$ phase precipitates can be formed by the shear process. As expected, the lower heating rate led to fine and homogeneous $\alpha$ phase precipitates.

In addition to Vickers hardness tests, the effects of the aging heat treatment conditions on mechanical behavior were investigated by analyzing tensile tests results. Samples subjected to aging at $500{ }^{\circ} \mathrm{C}$ for $30 \mathrm{~min}$, applying a heating rate of $1{ }^{\circ} \mathrm{C} / \mathrm{min}$, were chosen because of their fine and homogeneously distributed $\alpha$ phase precipitation in the $\beta$ phase matrix. The samples reached an ultimate tensile strength (UTS) of $765 \mathrm{MPa}$ and 19\% of elongation (EL). A solution heat-treated and water quenched Ti-30Nb-3Fe alloy presented an ultimate tensile strength close to $660 \mathrm{MPa}$ with $18 \%$ of elongation ${ }^{11}$. The aging heat treatment performed in this study increased the mechanical strength without loss of ductility. The high density of fine $\alpha$ precipitates acts as an obstacle to dislocation motion in the $\beta$ phase, providing increasing of hardness and mechanical strength ${ }^{29}$.

Figure 9 depicts the fracture surface obtained after tensile testing. Figure 9a shows the predominance of dimples of varied sizes, which is characteristic of the ductile failure mechanism. Moreover, the transgranular fracture shown in Figure $9 \mathrm{~b}$ exhibit areas formed by the quasi-cleavage mechanism, resulting in a mixed-mode fracture. The strength difference between $\alpha$ precipitates and $\beta$ matrix and consequent heterogeneous strain of phases leading a formation of microvoids on $\alpha / \beta$ interface following their coalescence. While the transgranular brittle portion of the fracture surface could be caused by slight $\alpha$ precipitation on grain boundary of $\beta$ phase, as reported by Sadeghpour et al. ${ }^{30}$.

Figure 10 compares the mechanical properties and costs of several biomedical alloys to those of Ti-30Nb-3Fe alloy. The mechanical properties of three of the selected alloys, namely, aged $\mathrm{Ti}-42 \mathrm{Nb}-2 \mathrm{Sn}^{31}$, aged $\mathrm{Ti}-35 \mathrm{Nb}-4 \mathrm{Sn}^{32}$, and Ti-32Zr-30 $\mathrm{Nb}^{33}$, were reported in the literature. All these alloys have similar UTS and lower elongation than those of the Ti-30Nb-3Fe alloy. The Ti-35Nb-7Zr-5 Ta (as-forged) and $\mathrm{Ti}-35 \mathrm{Nb}-7 \mathrm{Zr}-5 \mathrm{Ta}-2 \mathrm{Fe}$ alloys $^{34}$ exhibited lower UTS. The mechanical properties achieved in this study were compatible with the required for biomedical applications of Ti alloys ${ }^{35,36}$. The aged $\mathrm{Ti}-30 \mathrm{Nb}-3 \mathrm{Fe}$ presented adequate UTS allied to high ductility, which is advantageous for biomedical uses.

The low cost of Ti-30Nb-3Fe alloy is also one of its advantages compared to other biomedical alloys. The cost comparison depicted in Figure 10 was based exclusively on
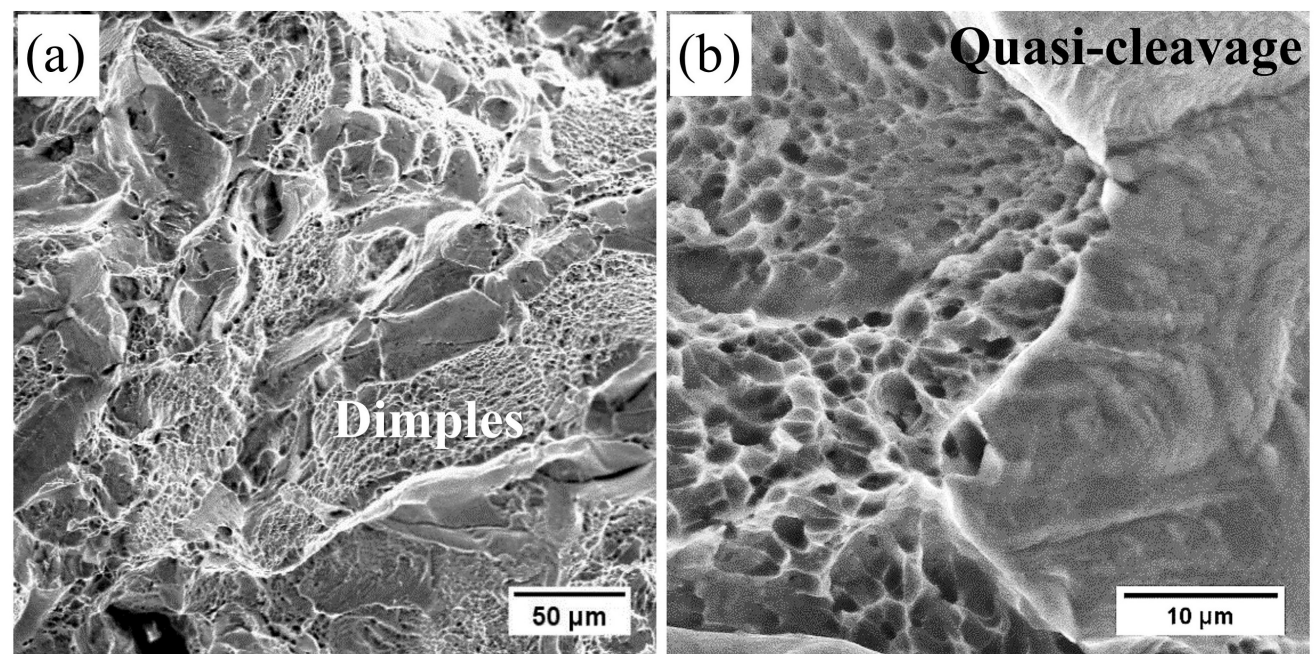

Figure 9. (a) and (b) Fracture surface of Ti-30Nb-3Fe alloy after aging at $500{ }^{\circ} \mathrm{C}$ applying a heating rate of $1{ }^{\circ} \mathrm{C} / \mathrm{min}$ for $30 \mathrm{~min}$.
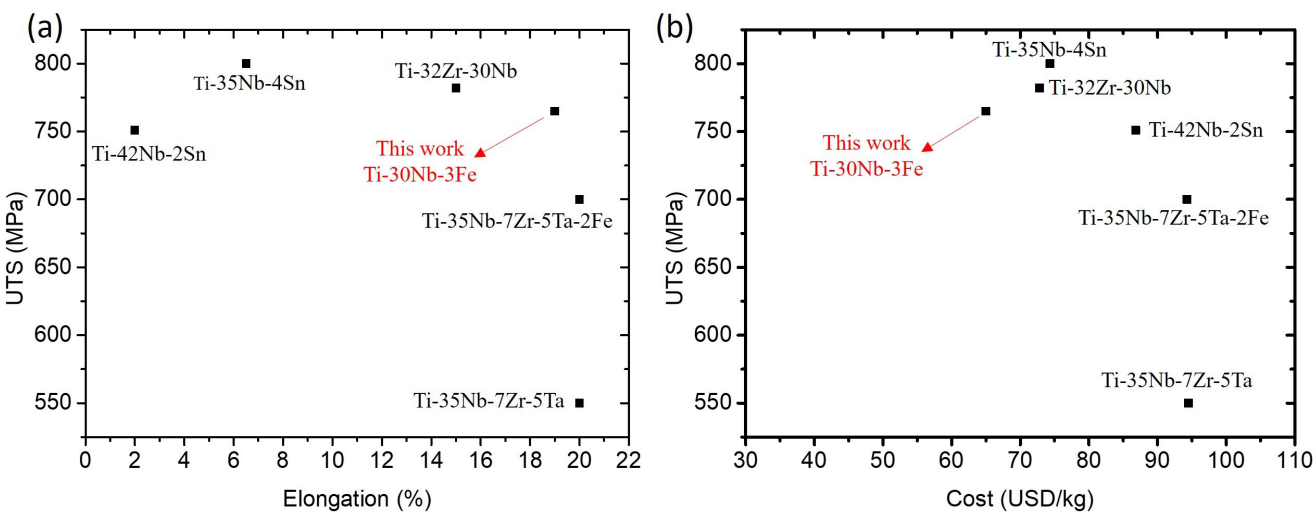

Figure 10. UTS vs. Elongation and UTS vs. costs of biomedical alloys described in the literature compared to those obtained in this study. 
the cost of raw materials ${ }^{37}$. This mention of raw materials costs is simply for comparative purposes to point out that the alloy of this study is composed of relatively inexpensive materials, although other factors such as production costs contribute to the final cost of alloys.

\section{Conclusions}

Based on the aforementioned results, it was concluded that the addition of Fe to $\mathrm{Ti}-30 \mathrm{Nb}$ alloy lowered the $\beta$-transus temperature to between 585 and $593{ }^{\circ} \mathrm{C}$. It also decreased the martensite start temperature to below room temperature, increased the precipitation temperature and lowered the dissolution temperature of the $\omega$ phase, and lastly, decreased the $\alpha$ phase precipitation temperature. Compared to different solution temperatures, $700{ }^{\circ} \mathrm{C}$ was found to be highly effective in obtaining small grain sizes.

The results of this study also confirmed that the heating rate to the aging temperature is of paramount importance. Low heating rates enable isothermal $\omega$ precipitation and growth, providing favorable conditions for $\alpha$ phase precipitation. High heating rates made $\omega$ precipitation more difficult, hindering $\alpha$ phase nucleation. As the final aging temperature was increased from 400 to $500{ }^{\circ} \mathrm{C}$, $\omega$-assisted precipitation of $\alpha$ phase in $\mathrm{Ti}-30 \mathrm{Nb}-3 \mathrm{Fe}$ became easier. Applying a final aging temperature of $500{ }^{\circ} \mathrm{C}$ and a $1{ }^{\circ} \mathrm{C} / \mathrm{min}$ heating rate led to more intense $\omega$ phase precipitation, and therefore, a higher density of fine and dispersed $\alpha$ phase precipitates. The parameters of the aging heat treatment also interfered in the resulting Vickers hardness and elastic modulus values.

Compared to the solution heat-treated and water quenching condition, the aging heat treatment of Ti-30Nb-3Fe alloy led to higher Vickers hardness and mechanical strength, without loss of ductility.

\section{Acknowledgments}

The authors gratefully acknowledge the LNNano (National Nanotechnology Laboratory) at the CNPEM (National Center for Research on Energy and Materials) for allowing access to its SEM facilities. We also acknowledge the financial support of the Brazilian research funding agencies FAPESP (State of São Paulo Research Foundation) for Grant \#2016/24693-3, CNPq (National Council for Scientific and Technological Development) for Grant \#405054/2016-5, and CAPES/PNPD (Coordination for the Improvement of Higher Education Personnel) for Grant \#88887.357955/2019-00. We thank the Brazilian Niobium Mining and Processing Company CBMM for supplying the $\mathrm{Nb}$ used in this study.

\section{References}

1. Banerjee D, Williams JC. Perspectives on titanium science and technology. Acta Mater. 2013;61(3):844-79. http://dx.doi. org/10.1016/j.actamat.2012.10.043.

2. Cotton JD, Briggs RD, Boyer RR, Tamirisakandala S, Russo P, Shchetnikov N, et al. State of the Art in Beta Titanium Alloys for Airframe Applications. JOM. 2015;67(6):1281-303.

3. Geetha M, Singh AK, Asokamani R, Gogia AK. Ti based biomaterials, the ultimate choice for orthopaedic implants A review. Prog Mater Sci. 2009;54(3):397-425. http://dx.doi. org/10.1016/j.pmatsci.2008.06.004.
4. Santhosh R, Geetha M, Nageswara Rao M. Recent developments in heat treatment of beta titanium alloys for aerospace applications. Trans. Indian Inst Met. 2017;70:1681-8. http://link.springer. com/10.1007/s12666-016-0985-6

5. Peters M, Hemptenmacher J, Kumpfert J, Leyens C. Structure and Properties of Titanium and Titanium Alloys. In: Leyens C, Peters M. Titanium and Titanium Alloys. Weinheim: Wiley; 2003. p. 1-36.

6. Cordeiro JM, Barão VAR. Is there scienti fi c evidence favoring the substitution of commercially pure titanium with titanium alloys for the manufacture of dental implants? Mater Sci Eng C. 2017;71:1201-15. http://dx.doi.org/10.1016/j.msec.2016.10.025.

7. Chaves JM, Florêncio O, Silva PS, Marques PWB, Afonso CRM. Influence of phase transformations on dynamical elastic modulus and anelasticity of beta Ti-Nb-Fe alloys for biomedical applications. J Mech Behav Biomed Mater. 2015;46:184-96.

8. Mantani Y, Tajima M. Phase transformation of quenched $\alpha^{\prime \prime}$ martensite by aging in Ti-Nb alloys. Mater Sci Eng A. 2006;438440(Spec. Iss.):315-9.

9. Salvador CAF, Dal Bó MR, Costa FH, Taipina MO, Lopes ESN, Caram R. Solute lean Ti-Nb-Fe alloys: an exploratory study. J Mech Behav Biomed Mater. 2016;2017(65):761-9.

10. Biesiekierski A, Wang J, Abdel-Hady Gepreel M, Wen C. A new look at biomedical Ti-based shape memory alloys. Acta Biomater. 2012;8(5):1661-9. http://dx.doi.org/10.1016/j. actbio.2012.01.018.

11. Lopes ÉSN, Salvador CAF, Andrade DR, Cremasco A, Campo $\mathrm{KN}$, Caram R. Microstructure, mechanical properties, and electrochemical behavior of Ti-Nb-Fe Alloys Applied as Biomaterials. Metall Mater Trans, A Phys Metall Mater Sci. 2016;47(6):3213-26. http://link.springer.com/10.1007/s11661016-3411-0.

12. Lee CM, Ju CP, Lin JHC. Structure - property relationship of cast Ti - Nb alloys. J Oral Rehabil. 2002;29:314-22.

13. Devaraj A, Joshi VV, Srivastava A, Manandhar S, Moxson V, Duz VA, et al. A low-cost hierarchical nanostructured beta-titanium alloy with high strength. Nat Commun. 2016;7(1):11176.

14. Nag S, Banerjee R, Srinivasan R, Hwang JY, Harper M, Fraser HL. Assisted nucleation and growth of?? precipitates in the Ti-5Al-5Mo-5V-3Cr-0.5Fe?? titanium alloy. Acta Mater. 2009;57(7):2136-47. http://dx.doi.org/10.1016/j. actamat.2009.01.007.

15. Li T, Kent D, Sha G, Dargusch MS, Cairney JM. The mechanism of $\omega$-assisted $\alpha$ phase formation in near $\beta$-Ti alloys. Scr Mater [serial on the Internet]. 2015 Jul [cited 2020 Jan 17];104:758. Available from: http://linkinghub.elsevier.com/retrieve/pii/ S1359646215001475

16. Zheng Y, Williams REA, Wang D, Shi R, Nag S, Kami $\mathrm{P}$, et al. Role of $\omega$ phase in the formation of extremely refined intragranular $\alpha$ precipitates in metastable $\beta$-titanium alloys. Acta Mater. 2016;103:850-8.

17. Ivasishin OM, Markovsky PE, Semiatin SL, Ward CH. Aging response of coarse-and fine-grained titanium alloys. Mat Sci Eng A-Struct 2005;405:296-305.

18. Bönisch M, Matthias B, Calin M, Giebeler L, Helth A, Skrotzki W. Composition-dependent magnitude of atomic shuffles in $\mathrm{Ti}$ - Nb martensites $\mathrm{Ti}$ - Nb martensites. J Appl Crystallogr. 2014;47:1374-79.

19. Zheng Y, Choudhuri D, Alam T, Williams REA, Banerjee R, Fraser HL. The role of cuboidal $\omega$ precipitates on $\alpha$ precipitation in a Ti-20V alloy. Scr Mater. 2016;123:81-5.

20. Azimzadeh S, Rack HJ. Phase transformations in Ti-6.8Mo4.5Fe-1.5Al. Metall Mater Trans, A Phys Metall Mater Sci. 1998;29(10):2455-67.

21. Kent D, Wang G, Wang W, Dargusch MS. Influence of ageing temperature and heating rate on the properties and microstructure of $\beta$ Ti alloy, Ti-6Cr-5Mo-5V-4Al. Mater Sci Eng A. 2012;531:98-106. 
22. Wain N, Hao XJ, Ravi GA, Wu X. The influence of carbon on precipitation of $\alpha$ in Ti-5Al-5Mo-5V-3Cr. Mater Sci Eng A. 2010;527(29-30):7673-83.

23. da Costa FH, Salvador CAF, de Mello MG, Caram R. Alpha phase precipitation in Ti-30Nb-1Fe alloys - phase transformations in continuous heating and aging heat treatments. Mater Sci Eng A. 2016;677:222-9.

24. Zhang Y, Liu H, Jin Z. Thermodynamic assessment of the $\mathrm{Nb}$-Ti system. Calphad [serial on the Internet]. $2001 \mathrm{Jun}$ [cited cited 2020 Jan 17];25(2):305-17. Available from: https://www. sciencedirect.com/science/article/abs/pii/S0364591601000517

25. Yolton CF, Froes FH, Malone RF. Alloying element effects in metastable beta titanium alloys. Metall Trans, A, Phys Metall Mater Sci. 1979;10(1):132-4.

26. Bönisch M, Panigrahi A, Calin M, Waitz T, Zehetbauer M, Skrotzki W, et al. Thermal stability and latent heat of $\mathrm{Nb}$-rich martensitic Ti-Nb alloys. J Alloys Compd. 2017;697:300-9.

27. Devaraj A, Williams REA, Nag S, Srinivasan R, Fraser HL, Banerjee R. Three-dimensional morphology and composition of omega precipitates in a binary titanium-molybdenum alloy. Scr Mater. 2009;61(7):701-4. http://dx.doi.org/10.1016/j. scriptamat.2009.06.006.

28. Kobayashi S, Takeichi T, Nakai K. Acceleration or Suppression of $\alpha$-Phase Precipitation Using Isothermal $\omega$ Phase in Ti-20 at.pet Nb Alloy. Metall Mater Trans A 2014;45(3):1217.

29. Ivasishin OM, Markovsky PE, Matviychuk YV, Semiatin SL, Ward CH, Fox S. A comparative study of the mechanical properties of high-strength $\beta$-titanium alloys. J Alloys Compd. 2008;457:296-309.

30. Sadeghpour S, Abbasi SM, Morakabati M, Bruschi S. Correlation between alpha phase morphology and tensile properties of a new beta titanium alloy. Mater Des. 2017;121:24-35.

31. Azevedo TF, Lima TN, de Blas JG, Pereira LC, Griza S. The mechanical behavior of TiNbSn alloys according to alloying contents, cold rolling and aging. J Mech Behav Biomed Mater. 2017;75:33-40.

32. Matsumoto H, Watanabe S, Hanada S. Beta TiNbSn Alloys with Low Young's Modulus and High Strength. Mater Trans. 2005;46(5):1070-8.

33. Ozan S, Lin J, Li Y, Wen C. New Ti-Ta-Zr-Nb alloys with ultrahigh strength for potential orthopedic implant applications. J Mech Behav Biomed Mater. 2017;75(Feb):119-27.

34. Kopova I, Stráský J, Harcuba P, Landa M, Ba L. Newly developed $\mathrm{Ti}-\mathrm{Nb}-\mathrm{Zr}-\mathrm{Ta}-\mathrm{Si}-\mathrm{Fe}$ biomedical beta titanium alloys with increased strength and enhanced biocompatibility. Mater Sci Eng C. 2016;60:230-8.

35. Niinomi M. Mechanical properties of biomedical titanium alloys. Mater Sci Eng A. 1998;243:231-6.

36. Yi R, Liu H, Yi D, Wan W, Wang B, Jiang Y, et al. Precipitation hardening and microstructure evolution of the Ti-7Nb-10Mo alloy during aging. Mater Sci Eng C. 2016;63:577-86.

37. Abd-elrhman Y, Gepreel MAH, Abdel-Moniem A, Kobayashi S. Compatibility assessment of new V-free low-cost Ti-4.7Mo4.5Fe alloy for some biomedical applications. Mater Des. 2016;97:445-53. http://dx.doi.org/10.1016/j.matdes.2016.02.110. 